\title{
Anizational justice and its relation to the administrative creativity of the employees in the auspices of youth at Fayoum University
}

\section{*Dr/ Moataz Ali Hassan}

\section{Introduction and problem of research:}

The mission of the university, in addition to scientific research and diverse literature useful to mankind, includes the education of successive generations of university youth to prepare it to play its role in leading all facilities in the country.(192: 4) In this context, specialized academic institutions have been established, called Youth Care, which includes qualified professionals who are able to deal with the university youth through the provision of a range of artistic, cultural, social and sports activities, and all these activities, although different in contents, An integrated and balanced growth of students in order to build their personalities, develop their abilities and refine their talents. (6:10).

However, many studies and research conducted on university student activity indicated that there are obstacles that prevent them from reaching their desired goals.

These studies have tried to develop suitable solutions to address these obstacles. To develop the programs of university student activity, and of course we will not be able to develop the capabilities of these workers without the constant motivation for creativity which is the key to the transition to the future.

Praven Gobta (2008) defines creativity as the ability to sense a problem that requires treatment and the ability to think differently to find appropriate solutions. (AbulKheir Abdel Tawab, 2015), quoted by Sayed Eid (2007) that the types of administrative creativity include the following (creativity expressiontechnological creativityinnovative creativity- creative innovation- imaginative

* Instructor of Sports Administration, Faculty of Physical Education, Beni Suef University. Assiut Journal For Sport Science Arts 
creativity), and confirms that the elements include the following (Originalityflexibility- fluency- sensitivity to problems- retention - risk acceptance - analysis and linkage - out of the ordinary). (23:2)

While Ahmed Azmi said that the most important obstacles to administrative creativity are (fear of criticismtendency to laziness- lack of self-confidence- fear of facing intellectual stagnation- low level of self-esteem- poor interest in creators- weak communication systems of the institution). (28: 3), and $\mathrm{Abu}$ al-Khair Abdul-Awad, 2015, adds some obstacles such as (adherence to procedures- low level of training- lack of appreciation of creators). (27:2)

In addition to the previous reasons, it is necessary to add an important reason, including the weakness of the system of incentives and material and moral assessment of the workers is what can be expressed as the absence of an element of organizational justice for the institution.

Hence, this study is intended to examine the relationship between organizational justice and the administrative creativity of young people working in one of the public universities, Fayoum University. Abtahal Talaat 2017 (Adel Adel Hassan 2005) defines organizational justice as the degree of achieving equality and integrity in the rights and duties among the members of the organization and its dimensions include the following:

-The justice of distribution: through the worker's assessment of justice in comparison to his contributions to work and his earnings, and may be compared with peers in the institution or with his counterparts from outside the institution.

\section{-The fairness of the procedures:}

By allowing individuals to express their opinion in the formulation and application of various procedures with the individual's assessment of the impact of this opinion on the decisions of the institution.

\section{-The fairness of transactions:}

Through the commitment of the owner of the authority to the limits of decency in dealing with employees without bias 
negatively or positively and objectively takes into account the decisions and mechanisms of the institution. (33:1)

Research Objective:

This study aims at monitoring the nature of the relationship between organizational justice and administrative creativity among the workers in the care of youth at Fayoum University.

The researcher assumes that there is a positive relationship between the dimensions of organizational justice and administrative creativity among the youth-

\section{Table (1)}

\section{Characterization of the sample and the research community}

\begin{tabular}{|c|c|c|c|c|c|c|}
\hline \multirow[b]{2}{*}{ serial } & \multirow[b]{2}{*}{ Class } & \multirow[b]{2}{*}{ Community } & \multicolumn{3}{|c|}{ The sample } & \multirow{2}{*}{$\begin{array}{l}\text { The ratio } \\
\text { of sample } \\
\text { with the } \\
\text { community }\end{array}$} \\
\hline & & & Exploration & Basic & Total & \\
\hline \multirow[t]{2}{*}{$T$} & & 1 & - & 1 & 1 & $\% 1 \ldots$ \\
\hline & $\begin{array}{l}\text { Departments } \\
\text { managers }\end{array}$ & $r \varepsilon$ & 1 . & 1. & r. & $\%$ \% \\
\hline \multirow[t]{2}{*}{ r } & $\begin{array}{l}\text { Sportive } \\
\text { specialists }\end{array}$ & r & 1. & 10 & ro & $\% \vee \wedge .1$ \\
\hline & Social workers & NV & 1. & «0 & 00 & $\%$ \%Tr.Y \\
\hline \multirow[t]{2}{*}{$r$} & Administrators & 19 & - & 10 & 10 & $\% \vee \wedge .9$ \\
\hline & $\begin{array}{ll}\text { Back } & \text { up } \\
\text { services } & \\
\end{array}$ & r & - & $1 \varepsilon$ & $1 \leq$ & $\% \uparrow \cdot . \wedge$ \\
\hline & Total & 114 & $r$. & $1 \cdots$ & Ir. & $\% \vee$. \\
\hline
\end{tabular}

- Data collection tools: - The researcher used the measure of organizational justice and the measure of administrative innovation to identify the sponsored workers at Fayoum University, which is practiced in a medium degree within the work environment of the university.

\section{Search procedures:}

\section{Methodology}

The researcher used the descriptive method in the survey method for its suitability and the nature of the study.

\section{Sample and society:}

The sample and the research community include the following categories in the following table:

\section{Assiut Journal For Sport Science Arts}


justice by Mohamed Ahmed Abbas (2003), which was codified by Mohamed Sayed Bashir (2012). It consists of three axes: distributive justice, procedural fairness and justice by transactions with a total of 20 words and a balance of three estimates - not agree) .

The researcher applied the scale to a number of (30) representing the survey sample from the members of the research community and outside the basic sample of the research to verify its validity and stability in the measurement of what was put for it.

The correlation between the score of each statement and the total score of the phrase in each axis, the correlation coefficients for each axis were calculated separately with the total number of axes according to the following tables.

As for the calculation of the stability coefficient, the researcher used the cronbach coefficient on the same survey sample. The coefficients ranged between $0.85-0.87$ and 0.92 for the total score of the scale. To a high degree of stability allows the application of the scale on the basic sample The following is a review of the tables:

coefficients were calculated

\section{Table (2)}

Demonstrate the correlation coefficient between the degree of each statement and the total degree of the axis to which it belongs

$$
\mathrm{N}=30
$$

\begin{tabular}{|c|c|c|c|c|c|c|c|c|c|}
\hline \multicolumn{2}{|c|}{ Distributive justice } & \multicolumn{4}{|c|}{ Performing justice } & \multicolumn{4}{|c|}{ Treatments justice } \\
\hline $\begin{array}{c}\text { The } \\
\text { phrase } \\
\text { no. }\end{array}$ & $\begin{array}{l}\text { Coefficient } \\
\text { of } \\
\text { correlation }\end{array}$ & $\begin{array}{c}\text { The } \\
\text { phrase } \\
\text { no. }\end{array}$ & $\begin{array}{l}\text { Coefficient } \\
\text { of } \\
\text { correlation }\end{array}$ & $\begin{array}{c}\text { The } \\
\text { phrase } \\
\text { no. }\end{array}$ & $\begin{array}{l}\text { Coefficient } \\
\text { of } \\
\text { correlation }\end{array}$ & $\begin{array}{c}\text { The } \\
\text { phrase } \\
\text { no. }\end{array}$ & $\begin{array}{l}\text { Coefficient } \\
\text { of } \\
\text { correlation }\end{array}$ & $\begin{array}{c}\text { The } \\
\text { phrase } \\
\text { no. }\end{array}$ & $\begin{array}{l}\text { Coefficient } \\
\text { of } \\
\text { correlation }\end{array}$ \\
\hline 1 &. .19 & \multirow{2}{*}{7} & \multirow{2}{*}{$\because V V$} & \multirow{2}{*}{$\checkmark$} & \multirow{2}{*}{.$\wedge r$} & $\overline{T H}$ &. $\mathrm{VO}$ & $\pi$ &. .77 \\
\hline r &.$\wedge \mathrm{V}$ & & & & & $1 \leqslant$ & $.0 \mathrm{~V}$ & 10 & $\cdot . \wedge 7$ \\
\hline$r$ & $\cdot \wedge \varepsilon$ & \multirow{2}{*}{$\wedge$} & \multirow{2}{*}{$\cdot \wedge \varepsilon$} & \multirow{2}{*}{9} & \multirow{2}{*}{.$\wedge \wedge$} & 17 &.$V Y$ & IV & $.7 \wedge$ \\
\hline$\xi$ &.$V^{\top}$ & & & & & 11 &. $.7 \wedge$ & 19 & .7. \\
\hline 0 & $\because V \cdot$ & 1. &.$V T$ & 11 & .7 & $r \cdot$ & .01 & - & - \\
\hline
\end{tabular}

Table (3)

Shows the correlation coefficient between the total axis and the total sum of the axes

Assiut Journal For Sport Science Arts 


\begin{tabular}{c|l|c}
\hline \hline Serial & \multicolumn{1}{|c|}{ The axis } & Coefficient of correlation \\
\hline \hline$r$ & Distributive justice & $\cdot V \vee$ \\
\hline$r$ & Performing justice & $\cdot .91$ \\
\hline$r$ & Treatments justice & $\cdot . \wedge \mathrm{r}$ \\
\hline \hline
\end{tabular}

\section{Table (4)}

The coefficient of correlation between the degree of each

statement and the total number of words as a whole is shown

\begin{tabular}{|c|c|c|c|c|c|c|c|}
\hline $\begin{array}{l}\text { Coefficient } \\
\text { of } \\
\text { correlation }\end{array}$ & $\begin{array}{c}\text { The } \\
\text { phrase } \\
\text { no. }\end{array}$ & $\begin{array}{c}\text { Coefficient } \\
\text { of } \\
\text { correlation }\end{array}$ & $\begin{array}{c}\text { The } \\
\text { phrase } \\
\text { no. }\end{array}$ & $\begin{array}{c}\text { Coefficient } \\
\text { of } \\
\text { correlation }\end{array}$ & $\begin{array}{c}\text { The } \\
\text { phrase } \\
\text { no. }\end{array}$ & $\begin{array}{c}\text { Coefficient } \\
\text { of } \\
\text { correlation }\end{array}$ & $\begin{array}{c}\text { The } \\
\text { phrase } \\
\text { no. }\end{array}$ \\
\hline$\because$ Or & 17 & $.7 \leqslant$ & 11 &.$V T$ & 7 & .00 & 1 \\
\hline$\because \leqslant \Lambda$ & IV & $.7 V$ & Ir & $\because V Y$ & V & $\because 7 r$ & Y \\
\hline$\because \leqslant \Lambda$ & 11 & .71 & $1 \pi$ &.$V 7$ & $\Lambda$ & .77 & $r$ \\
\hline$\cdot v 1$ & 19 & .77 & $1 \varepsilon$ & $\because v 1$ & 9 & .00 & $\varepsilon$ \\
\hline$\because V Y$ & $r$. & $\because V$. & 10 &.$T V$ & 1. & .79 & 0 \\
\hline
\end{tabular}

Second: Use of the researcher the measure of administrative innovation (prepared by Abu Al-Khair Abdul Tawab Taha 2015) and consists of eight axes (originality - fluency - flexibility - sensitivity to problems - acceptance of risk - analysis and linkage - out of the ordinary - keep the trend) total number (82) .

The researcher applied the exploratory sample to (30) members of the research community and outside the basic sample members in order to verify the validity and stability of the scale in its use in what was developed for it.

The correlation coefficients were calculated between the score of each statement and the total score of the words for each axis and the total number of axes

And then calculate the coefficient of cronbach stability of the axes also, which came all high indicating the accuracy of the scale and stability as presented as follows: 
Table (5)

The correlation coefficients for each axis are shown in the total sum of the axes $(n=30)$

\begin{tabular}{|c|c|c|c|c|c|}
\hline \multirow{2}{*}{ Serial } & \multirow{2}{*}{ The axe } & \multirow{2}{*}{$\begin{array}{c}\text { Number } \\
\text { of } \\
\text { phrases }\end{array}$} & \multicolumn{2}{|c|}{ Treatments } & \multirow{2}{*}{$\begin{array}{l}\text { The stability } \\
\text { coefficient of the } \\
\text { axle as a whole } \\
\text { Alfa corenbach }\end{array}$} \\
\hline & & & From & To & \\
\hline 1 & Authenticity & 1. &.$\leqslant 9$ &..$V 7$ & $\cdot .7 Y$ \\
\hline$r$ & Fluency & $V$ & 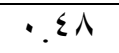 & $\cdot \Delta r$ & .07 \\
\hline$r$ & Flexibility & 10 &.$\leqslant 9$ & .71 & $\because V V$ \\
\hline$\varepsilon$ & Accept risk & IT &.$\leqslant 7$ & .71 &. $.7 \wedge$ \\
\hline 0 & $\begin{array}{l}\text { Analysis and } \\
\text { linkage }\end{array}$ & $\wedge$ & $\ddots \leqslant V$ & .79 & $.0 r$ \\
\hline 1 & $\begin{array}{c}\text { Allergies and } \\
\text { problems }\end{array}$ & 9 & $\because \leqslant V$ & $.7 \varepsilon$ & זד. \\
\hline v & $\begin{array}{c}\text { Out of the } \\
\text { ordinary }\end{array}$ & 11 & 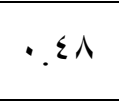 & $\cdot .71$ & .71 \\
\hline$\wedge$ & $\begin{array}{l}\text { Keep the } \\
\text { trend }\end{array}$ & 1 . & $\because \leqslant V$ & $\because \vee \varepsilon$ & $\because V \varepsilon$ \\
\hline
\end{tabular}

Search application: -

The researcher applied and implemented the research on the exploratory sample during December 2016, while applying it to the basic sample for the period from 1st March 2017 to mid 2016, on the staff of youth care at faculties of

Fayoum University and the employees of the general administration of youth care at the university.

\section{Research results:}

The following are the main results of the research, which are as follows:

First: Organizational Justice Results:

\begin{tabular}{|c|c|c|c|c|c|c|c|c|c|c|}
\hline \multicolumn{3}{|c|}{ Treatments justice } & \multicolumn{3}{|c|}{ Performing justice } & \multicolumn{3}{|c|}{ Distributive justice } & \multirow[t]{2}{*}{ Description } & \multirow[t]{2}{*}{ Class } \\
\hline $\begin{array}{c}\text { Not } \\
\text { agree }\end{array}$ & Neutral & Agree & $\begin{array}{c}\text { Not } \\
\text { agree }\end{array}$ & Neutral & Agree & $\begin{array}{c}\text { Not } \\
\text { agree }\end{array}$ & Neutral & Agree & & \\
\hline 1 & $r$ & V & T & $r$ & $\mathrm{~V}$ & $\Lambda$ & $r$ & 1 & No & \multirow{2}{*}{$\begin{array}{c}\text { Managers } \\
\mathrm{N}=11\end{array}$} \\
\hline$\% 9.1$ & $\%$ \% . & *\%า & $\% \backslash \wedge . r$ & $\% \backslash \wedge . r$ & *\%าT. 7 & $* \% \vee r . V$ & $\% \backslash \wedge . Y$ & $\% 9.1$ & Ratio & \\
\hline IT & ru & ir & 11 & $\varepsilon$ & 9 & $\varepsilon r$ & $1 \cdot$ & $\wedge$ & No & \multirow{2}{*}{$\begin{array}{c}\text { Specialists } \\
\mathrm{N}=60\end{array}$} \\
\hline$\%$ r. & $* \%$ \%. & $\%$ r. & $\% 11.10$ & $* 077 . \wedge$ & $\% 10$ & $* \% \vee$ & $\% 17.0$ & $\% 1 \Gamma .0$ & Ratio & \\
\hline$\varepsilon$ & 0 & $r \cdot$ & 0 & 0 & 19 & YI & 0 & $r$ & No & \multirow{2}{*}{$\begin{array}{l}\text { Administrative } \\
\text { and support } \\
\text { services } \\
\mathrm{N}=29\end{array}$} \\
\hline$\%)$ ir.人o & IV.YO & $* \% 7 \wedge .9$ & $\%)$ I. To & IV.YO & $* \% 70.0$ & $* \% \vee Y . \varepsilon$ & $\%$ IV.YO & $\% 1 \cdot . r o$ & Ratio & \\
\hline
\end{tabular}


And weak impact.

** There were statistically significant differences between the three sample groups in the procedural justice and justice in transactions in favor of the (impartial) response of the group of specialists while the same response came to the members of the group of managers and the group of administrators and services in the direction of response Reflecting the different vision of the sample where the group of managers and the group of administrators and services supported the existence of justice in the transactions and fairness in the various procedures within the work system under the auspices of youth at Fayoum University, while the vision came to the members of the group of specialists to (7), while contradicting the result of Khaled Zulfikar's study (6), and attributed the researcher to the difference of vision among the workers, while we find specialists Are reluctant to recognize the existence of procedural justice and fair transactions, but higher functional categories such as managers and other categories are lower, such as administrators and support workers. Both categories are affected by fairness in procedures and in transactions more than the middle category between them.

Second: - The results of administrative innovation:

*. The results were to confirm the ability of the sample workers in the research to practice the behaviors of administrative innovation in a different and vary according to degree and job title as follows:

- The group of specialists in the first place and then the group of managers, which came in second place before the group of administrators and support services, which came in third place in the total number of administrative creativity to guide the arrangement of them according to the practice of administrative creativity behavior in the eight axes of the scale as a whole.

-There are statistically significant differences in the risk acceptance and sensitivity of the problems in the direction of (approval) for the group of specialists compared to the group of managers and the group of administrators and support services whose

Assiut Journal For Sport Science Arts 
responses were directed to (to a certain extent)

- There are statistically significant differences in the ability to analyze and link in the direction of (approval) for the group of managers compared to the group of specialists and the group of administrators and support services whose responses were directed to (to a certain extent). - There were no statistical differences in the other axes, namely originality, fluency, flexibility, out of the ordinary and keeping the trend. The responses of the three groups were directed to the response (to a certain extent).

* The researcher attributed the previous results (on the order) that the group of specialists progressed in order to practice creativity because most of them are young and enthusiastic to work with the ability to risk not to be in positions of responsibility, such as the group of managers who are adhering to controls and abide by commitments.

As for the ability of managers to analyze and connect, the researcher attributes their progress from the other two groups to the previous experience and the length of the term of the members of the group of managers, which gives them greater ability to understand positions and analyze them to reach the appropriate solutions by re-linking positions with each other.

While the sample agreement to respond to the approval to some extent in the other axes without any indication of statistical differences, including a balanced practice of administrative creativity behaviors of all members of the sample, which is attributed to the researcher to agree on the in the provision of programs and services students, which is also confirmed by the adoption of the University For a consistent policy known among Egyptian universities over the past years.

The

previous discrepancy and variance is consistent with the variance and variability of the research sample according to the results of the studies of Abulhair AlTawab (2) 2015, Ahmed Azmi (3) 2011, Khalid Zulfiqar (6) 2014.

\section{Research Conclusions:}

In the light of the previous results, the researcher 
concluded that the hypothesis of the research was achieved through the following:

1/ Different opinions of the research sample of youth care workers at Fayoum University on organizational justice where the group of managers and the group of administrators and supporting services agreed on the existence of organizational justice in two axes (procedures - transactions), while the group of specialists did not agree to this presence to justice in the proceedings Or transactions, their responses were neutral in these two axes.

2/ Unanimously agree the views of the research sample of workers in the care of young people at Fayoum University on the absence of distributive justice related to the material return and incentives, salaries and rewards that they receive, which they do not correspond with the hours and the workload of the care of young people other than the lack of objectivity and transparency in the distribution available to them.

$r /$ Practitioners working under the auspices of youth at Fayoum University practice the behaviors of managerial innovation at work, regardless of their levels, grades and job titles, although the total number of creativity varies with them, where the group of specialists increases to practice well and then slightly less among the group of managers who practice administrative creativity at an acceptable level, Administrative and support services who practice management creativity in a medium degree

4/ There is a positive relationship in the positive direction between the levels of administrative creativity of the workers under the auspices of young people at Fayoum University and between the organizational justice in the axes of procedural justice and justice in transactions, except for the group of specialists who practice administrative innovation as a permanent behavior in the work despite not approving or refusing to exist Justice in these two axes.

\section{Research Recommendations:}

In the light of the previous conclusions, the research and researcher recommend the need to encourage the creators of the youth care workers at Fayoum University and help them to present their ideas and develop 
their abilities in developing solutions. Despite the unanimous rejection of the absence of distributive justice,

The work and its activities are sponsored by young people at Fayoum University, but they practice creativity to varying degrees, indicating their practice of creativity in the absence of this kind of distributive justice.

To address any problems with the work by:

- Dissemination of the culture and atmosphere of creativity among youth-sponsored workers at Fayoum University.

- Honoring and distinguishing the creators of youth care workers at Fayoum University through rewards and incentives and taking them into consideration when choosing to hold leadership or higher positions for higher degrees.

- Taking into consideration the axes of organizational justice among the youth care workers at Fayoum University, especially distributive justice.

\section{References}

1- Abdullah Mohamed Ahmed Abbas 2003: The Effect of Organizational Justice on the Effectiveness of Job Performance by Application to Faculty Members at Kuwait
University, Unpublished Master Thesis at the Faculty of Commerce, Ain Shams University.

2- Abu Al-Khair Abdul Tawab Taha 2015 AD: Administrative creativity in the staff of the Directorate of Youth and Sports in Beni Suef, unpublished Master thesis Faculty of Physical Education, Beni Suef University.

\section{3- Adel Hassan Sayed 2005:} organizational justice and its relationship to the effectiveness of performance and job satisfaction in the care of youth in Egyptian universities, research published in the Journal of Sports Sciences Faculty of Physical Education in Menia.

\section{4- Ahmed Azmi Imam 2011:}

The impact of a proposed administrative development program on the administrative creativity of students of the Faculty of Physical Education, unpublished $\mathrm{PhD}$ thesis Faculty of Physical Education, Minia University, (2011).

\section{5- Ahmed Lotfi Sayed 1986:}

Story of my life, the Egyptian General Book Organization, Cairo.

6- Braven Gupta 2008: Administrative Innovation in the 21st Century (Ahmed Al- 
Magri), Dar Al-Fajr Publishing and Distribution, First Edition, Cairo.

7- Colquitt \& Judge 2004 : organizational justice and stress, the mediating role of work family conflict, journal of applied psychology

Washington, Jun .

8- Mohamed Sayed Bashir 2012: the impact of organizational justice on the effectiveness of the performance of employees in the departments of youth and sports in Upper Egypt, unpublished Master thesis Faculty of Physical Education in Assiut.

9- Moataz Ali Hassan 2012:

A proposed model for funding sports activity in Egyptian universities, unpublished $\mathrm{PhD}$ thesis at the Faculty of Physical Education for Boys, Helwan University.

\section{0- Khaled Zulfikar Murad,} 2014: A proposed scenario to select youth leadership leaders in Assiut University in the light of leadership styles and administrative creativity, Master's thesis, Faculty of Physical Education, Assiut University.

11- Talaat Hassan 2017: Administrative Networks and its Relation to Organizational Justice among Workers in Youth Centers in Minya Governorate, Unpublished Master Thesis, Faculty of Mathematical Education, Beni Suef University. 